\title{
NUEVO MARCO JURÍDICO DE LA SALUD MENTAL EN URUGUAY Ley $\mathrm{N}^{\circ} 19.529$ de 19 de septiembre de 2017
}

\begin{abstract}
RESUMEN. Análisis del nuevo régimen establecido por la Ley $\mathrm{N}^{\circ} 19.529$ en cuanto a los derechos de los pacientes con trastornos mentales, el reconocimiento de cierta capacidad de obrar para los incapaces estén o no interdictos, el ajuste a la Declaración Universal de los Derechos Humanos de la ONU de 10 de diciembre de 1948 y a las Convenciones Internacionales sobre discapacitados aprobadas por Uruguay, el problema de la disposición de derechos personalísimos en caso de incapaces, la posibilidad de otorgar consentimiento informado por este tipo de pacientes, el régimen de la hospitalización voluntaria, involuntaria y judicial y los aspectos orgánicos de la nueva ley.
\end{abstract}

PALABRAS CLAVES. Salud mental. Incapaz. Interdicción, Derechos personalísimos. Consentimiento informado. Hospitalización involuntaria.

\begin{abstract}
Analysis of the new regime established by Law No. 19.529 regarding rights of patients with mental disorders, recognition of certain capacity to act, whether or not they are declared legally incapable, adjustments to the Universal Declaration of Human Rights of the UN dated December 10, 1948 and to the International Conventions on disabled persons approved by Uruguay, the problem of the disposal of personal rights in case of incapability, the possibility of granting informed consent
\end{abstract}

" Doctora en Derecho por la Universidad de Montevideo (2005), Máster en Derecho Administrativo Económico (2011), Profesor Adscripto de Derecho Administrativo I y II en la Universidad de Montevideo (2006-2018), Profesora de Derecho Público en el Posgrado de Gestión Financiera en Instituciones Públicas de la Facultad de Ciencias Económicas de la Universidad de la República (2018). Correo electrónico: natalia.veloso@delpiazzo.com 
for this type of patients, voluntary, involuntary and judicial hospitalization regimes as well as of organic aspects of the new law.

KEYWORDS. Mental health. Legally incapable. Personal rights. Informed consent. Involuntary hospitalization.

\section{PLANTEO DEL TEMA}

La regulación de la Salud Mental tiene la particularidad de establecer un régimen de derechos y obligaciones para un colectivo de la población que padece de trastornos que afectan su capacidad de discernimiento y su capacidad de auto conducirse en la vida civil.

En este contexto, estamos frente a sujetos de derecho que, en mayor o menor medida, requieren de asistencia para su obrar jurídico y por lo tanto, necesitan también de un régimen especial que les de amparo.

Sin perjuicio de ello, la inmensa diversidad y grados de trastornos mentales que puede padecer una persona, hacen que el mundo vaya lentamente superando el viejo paradigma por el cual la incapacidad equivale a supresión total de la capacidad de obrar, para poner en el centro al sujeto de derecho y contemplar, en la medida que su condición mental se lo permita, cierta capacidad de obrar como puede ser la de trabajar, otorgar consentimiento informado, contraer matrimonio, consentir la donación de órganos, etc.

Nuestro país, no es ajeno a este proceso y es en función de ello, que, en el año 2017, ha aprobado una nueva Ley de Salud Mental que viene a sustituir a su antecesora (la Ley $\mathrm{N}^{\circ}$ 9.581 de 24 de agosto de 1936 denominada "Ley de Psicópatas", que reguló la Salud Mental por más de 80 años en Uruguay $^{1}$ ) y viene asimismo a ponerse a tono con el enfoque de la Convención Americana de Derechos Humanos (Pacto de San José de Costa Rica) aprobada por la Organización de Estados Americanos (OEA) el 22 de noviembre de 1969 y ratificada por Uruguay por la Ley $\mathrm{N}^{\circ} 15.737$ de 8 de marzo de 1985; con la Convención sobre los Derechos de las Personas con Discapacidad aprobada por la Organización de las Naciones Unidas (ONU) en Nueva York el 3 de abril de 2007 y ratificada en nuestro país por la Ley $\mathrm{N}^{\circ} 18.418$ de 20 de noviembre de 2008 y con la Convención Interamericana para la Eliminación de todas las Formas de Discriminación contra las Personas con Discapacidad aprobada por la OEA en Guatemala el 7 de junio de 1999 y ratificada por Uruguay por Ley $\mathrm{N}^{\mathrm{o}} 17.330$ de 9 de mayo de 2001.

En este contexto, deviene fundamental analizar cuáles han sido los cambios más significativos en materia de regulación de salud mental, así como también analizar, cuáles son los principales problemas que ha planteado el nuevo articulado.

\section{DISPOSICIONES GENERALES}

El art. $1^{\circ}$ de la Ley establece que el objeto de la presente norma es "garantizar el derecho a la protección de la salud mental de los habitantes residentes en el país", con lo cual queda claro que se reconoce dicho derecho a todos los habitantes que residan en el país, con

${ }^{1}$ Saúl D. CESTAU - "Personas”, F.C.U., Montevideo, 1997, Volumen II, pág. 123 y sgtes. 
independencia de si los mismos son o no usuarios del Sistema Nacional Integrado de Salud (en adelante, SNIS).

Por otra parte, se reconoce que garantizar dicho derecho supone acciones no solo de tratamiento y de rehabilitación, sino también acciones tendientes a la promoción y sobre todo, prevención de trastornos mentales.

Asimismo, se establece que las disposiciones de esta ley son de orden público por lo que no pueden ser dejadas de lado por acuerdo de partes. Esto es, que con independencia de cuáles sean las condiciones asistenciales que ofrezcan centros públicos o privados, las disposiciones de esta ley rigen para todos los centros de asistencia del país y para todos los pacientes (usuarios o no del SNIS) que padezcan de un trastorno de la salud mental.

En cuanto a las definiciones, el art. $2^{\circ}$ define el concepto de Salud Mental como "un estado de bienestar en el cual la persona es consciente de sus propias capacidades, puede afrontar las tensiones normales de la vida, trabajar de forma productiva y fructífera y es capaz de hacer una contribución a su comunidad".

En consecuencia, la determinación de la sanidad mental de un individuo va a depender de varios factores que serán tenidos en cuenta en forma dinámica y a lo largo del tiempo, conforme a las circunstancias históricas y personales de dicho paciente y al cabo de las cuales deberá apreciarse si dicho sujeto puede manejar habitualmente el día a día, trabajar y hacer de alguna forma una contribución social.

Para completar dicho concepto, la ley también define el trastorno mental como la "existencia de un conjunto de síntomas y conductas clínicamente reconocibles, asociado en la mayoría de los casos con el malestar y con la interferencia con el funcionamiento personal. La desviación social o el conflicto, tomados aisladamente y sin estar ligados a disfunciones personales, no deberán incluirse en la noción de trastorno".

En efecto, tal como puede apreciarse, las situaciones puntuales que no están ligadas a una disfunción personal, no pueden ser caracterizadas como trastornos mentales ya que la ley exige cierta condición de continuidad, permanencia en el tiempo y atribución a causas funcionales para ingresar dentro del concepto jurídico de trastorno mental.

\section{DERECHOS DE LOS PACIENTES CON TRASTORNOS DE SALUD MENTAL}

Los pacientes con trastornos de salud mental quedan alcanzados, como cualquier otra persona, por las disposiciones propias de la Ley $\mathrm{N}^{\circ} 18.335$ de 15 de agosto de 2008 (Derechos del Paciente) $)^{2}$.

Sin perjuicio de ello, el art. 6 de la Ley $\mathrm{N}^{\circ} 19.529$ realiza una enumeración de los derechos de los pacientes usuarios de servicios de salud mental, que recoge las particularidades propias de este tipo de patologías y que pueden ser sistematizados de la siguiente manera.

${ }^{2}$ Ver: Bárbara DEI-CAS - "Derechos y Deberes de los Pacientes y Usuarios" en Carlos E. DELPIAZZO (Coordinador) - "Régimen de Asistencia a la Salud", F.C.U., Montevideo, 2018, Segunda Edición Ampliada y Actualizada, pág. 175 y ss.). 
En primer lugar, se establecen derechos derivados de la calidad de seres humanos tales como el respecto por la dignidad (lit. a); el respeto por su singularidad derivada de la diversidad de sus valores, orientación sexual, cultural, ideológica y religiosa (lit. b), el derecho a recibir una atención humanizada (lit. d), a estar acompañado por sus familiares y/o allegados durante el tratamiento (i); el derecho a no ser explotado o estigmatizado (lit. n) y el derecho a que se respete su intimidad y privacidad (lit. p)

En segundo lugar, se establece que el paciente tiene derecho a ser reconocido siempre como sujeto de derecho (lit. c), disponiéndose la alternativa terapéutica que indicada para su situación que menos restrinja sus derechos y libertades (lit. e), promoviéndose el mayor grado de autonomía posible para su reinserción familiar, laboral y comunitaria (lit. j).

En efecto, el lit. e) del mencionado artículo establece que dicha calidad de sujeto de derecho debe ser respetada durante su internación, pudiendo el paciente "ejercer sus derechos como cualquier otra persona usuaria de los servicios de salud del prestador correspondiente".

Respecto de este artículo, se ha planteado la interrogante acerca de cómo compatibilizar esta disposición con las limitaciones de la capacidad de obrar que nuestro ordenamiento impone a los incapaces.

En efecto, podría suceder que durante el período de su internación, debido al trastorno padecido, el paciente se viera impedido de ejercer ciertos derechos como el de no recibir sedación, el de abandonar la institución, disponer de sus bienes, recibir visitas, etc.

En estos casos, parece claro que existen limitaciones al ejercicio de sus derechos que a primera vista parecerían ser contradictorias con lo dispuesto por el art. 6 lit. e de la Ley, que expresamente prevé que el paciente pueda: "ejercer sus derechos como cualquier otra persona usuaria de los servicios de salud del prestador correspondiente".

Para resolver dicho punto, debe tenerse presente que el principio general es que los derechos de cualquier sujeto sólo pueden ser limitados por una ley dictada por razones de interés general (art. 7 de la Constitución). Asimismo, el principio debe ser siempre la libertad, estando permitido todo aquello que no esté prohibido por la ley (art. 10 de la Constitución).

El espíritu de la norma es consagrar la libertad como principio. Esto es, que el paciente internado contra su voluntad, no pierda por ese hecho todos sus derechos, sino que, por el contrario, los conserve. La limitación de los derechos debe ser considerada de forma restrictiva, ya que el principio general es la libertad.

En este contexto normativo, podríamos distinguir al menos tres grandes categorías de restricciones en la internación involuntaria:

a) las reconocidas por la propia ley: en estos casos no hay problema ya que las mismas tienen base legal (ej.: restricciones a las visitas);

b) las que derivan necesariamente de las razones por las cuales se dispuso la internación involuntaria: esto es, las tendientes a evitar que el paciente atente contra sí mismo o contra terceros o las necesarias para poder llevar adelante el tratamiento para el cual fue internado (ej.: sedación). En estos casos, se entiende que la base legal para este tipo de restricciones a la libertad está implícita en la 
disposición legal que habilita este tipo de internación. Por lo que no habría problemas respecto de las mismas; $y$

c) las restantes: es para estos casos que la disposición a estudio resulta importante, pues para estos casos no existiría base legal para realizarlas, debiéndose el profesional y la institución actuante, abstenerse.

Esta interpretación, parece ser la única compatible con la ya mencionada Convención sobre los Derechos de las Personas con Discapacidad, aprobada por la Organización de las Naciones Unidas y ratificada por Uruguay mediante la Ley $\mathrm{N}^{\circ} 18.418$ y con la Ley $\mathrm{N}^{\circ}$ 18.651 de 19 de febrero de 2010 sobre Protección Integral de Personas con Discapacidad ${ }^{3}$.

Dichas leyes, al igual que la Ley de Salud Mental, determinan una verdadera inversión de la lógica de los Códigos decimonónicos conforme con los cuales, un trastorno mental o discapacidad equivalía necesariamente a una incapacidad absoluta que suprimía por completo la capacidad de obrar, sin contemplar matiz alguno en las diferentes situaciones que los pacientes podrían plantear.

En este sentido, se ha señalado con acierto que: "el régimen impuesto en el siglo XIX en la época de la codificación era poco apropiado para disciplinar todas estas situaciones, por tratarse de un sistema de tutela rígido -no graduable-, que si bien podía ser razonable para los que padecieran una discapacidad profunda, era injustificable para los que solo tenían alguna debilidad o cierto retraso mental, hipótesis en que la mejor solución pasa por detectar una tutela graduada, adecuada para su grado de capacidad"4 5.

En el mismo sentido se ha sostenido que: "El paradigma de interdependencia establece que la capacidad y el apoyo pueden ser co-términos. Una persona con discapacidad no tiene que ser declarada incapaz para recibir apoyo. Consecuentemente la CDPD reconoce que una persona con discapacidad puede no necesitar apoyo para ejercitar su capacidad, sin embargo, la obtención de apoyo no es razón suficiente para concluir que no existe capacidad. Este paradigma de interdependencia que permite que la autonomía y el apoyo coexistan es un gran avance que la Convención ha logrado al establecer un régimen de derechos para las personas con discapacidad". ${ }^{6}$

Tratando de dar solución a este tema, el Código General del Proceso previó un "estadio intermedio entre la capacidad y la incapacidad absoluta del mayor de edad" habilitando al Juez a adoptar medidas ajustadas a la situación del incapaz como el "nombramiento de un

${ }^{3}$ Ver: "Carlos E. DELPIAZZO - "Alcance del rol tutelar del Estado a menores, discapacitados y adultos mayores” en Anuario Uruguayo Crítico de Familia y Sucesiones (Montevideo, 2016), N 4, pág. 135 y sgtes.; y "Derecho Administrativo Especial", A.M.F., Montevideo, 2017, volumen 2, tercera edición actualizada y ampliada, pág. 173 y sgtes.

${ }^{4}$ Walter HOWARD - "Derecho de la Persona", Universidad de Montevideo, 2018, Volumen II, pág. 553.

${ }^{5} \mathrm{Al}$ respecto se ha señalado también que: "Es que la interdicción, como instituto creado con el fin de proteger al incapaz: "no se adapta a las necesidades concretas y variables de cada sujeto y que comporta consecuencias socio jurídicas particularmente duras para el interdicto: no puede contratar, no puede contraer matrimonio, su voluntad es básicamente irrelevante, jurídicamente no cuenta. Impide en una palabra toda expresión de la personalidad realizada a través de actos jurídicos (Jorge GAMARRA y Juan E. BLENGIO - "Tratado de Derecho Civil Uruguayo”, F.C.U., 2001, Tomo X, 5 Edición, pág. 168 y ss.).

${ }^{6}$ Amita DHANDA- "Construyendo un nuevo léxico de derechos humanos: La Convención sobre los Derechos de las personas con discapacidad” en SUR, Revista internacional de Derechos Humanos, Año 5, Número 8, Junio de 2008, Edición en español, pág. 48. 
curador interino, la asistencia, la administración provisoria de bienes y cualquier medida

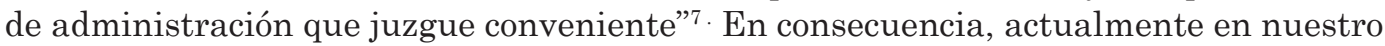
ordenamiento el Juez cuenta con instrumentos jurídicos que le permiten adaptar las restricciones a la capacidad de obrar al nivel de incapacidad que posee cada individuo.

En tercer lugar, se encuentran los derechos relativos al deber de información ${ }^{8}$ tales como recibir información completa y comprensible sobre su situación, sus derechos, las alternativas y tratamientos terapéuticas (lit.f) y el acceder a su historia clínica (lit. k).

En efecto, la Ley de Salud Mental sigue la línea de la Ley N ${ }^{\circ} 18.335$ (Derechos del Paciente) que reconoce expresamente el derecho del paciente a estar debidamente informado.

En la misma línea, el art. 13 de la Ley $\mathrm{N}^{\circ}$ Ley Nº 19.286 de 19 de octubre de 2014 (Código de ética Médica) establece que todo paciente tiene derecho a:

a) recibir información completa, veraz y oportuna sobre las conductas diagnósticas o terapéuticas que se le propongan, incluyendo las alternativas disponibles en el medio;

b) que se le comuniquen los beneficios y los riesgos que ofrecen tales procedimientos, en un lenguaje comprensible, suficiente y adecuado para ese determinado paciente;

c) que se respete la libre decisión del paciente, incluido el rechazo de cualquier procedimiento diagnóstico o terapéutico propuesto, en el marco de las normativas vigentes. En ese caso le informará sobre los riesgos o inconvenientes de su decisión. El médico podrá solicitar al paciente o a sus responsables, luego de la total y completa información del procedimiento propuesto, firmar un documento escrito en el que conste ese rechazo y en caso que no se lograra, dejar constancia en la historia clínica; y

d) a ser informado de los cambios eventuales en el plan diagnóstico o terapéutico, y en caso de su traslado a otro servicio o centro asistencial, informarle de los motivos del mismo.

Asimismo, se entiende que existe "un deber general de mantener al paciente siempre informado, deber que ya se encuentra consagrado en el art. $36^{\circ}$ del Decreto $\mathrm{N}^{\circ} 258 / 992$ de 16 de junio de 1992 al prescribir que aquel "tiene derecho a recibir información completa sobre el diagnóstico de su enfermedad, el tratamiento y el pronóstico".

En el caso particular de los pacientes con un trastorno mental, puede suceder que el suministro de determinada información sobre su condición de salud, sea contraproducente para su tratamiento o directamente, por la condición de su patología, sea peligroso transmitírsela al paciente (ej.: paciente paranoide).

En estos casos, entendemos que estamos frente a una excepción al deber de información de las consagradas por el art. 13 lit. c) de la Ley $\mathrm{N}^{\circ}$ Ley $\mathrm{N}^{\circ}$ 19.286, al tenor del cual "en los casos excepcionales en que esa información pudiese ocasionar efectos nocivos en la salud física o psíquica del paciente, podrá limitarla o retrasarla".

${ }^{7}$ Jorge GAMARRA y Juan E. BLENGIO, Ob. Cit. pág. 171.

${ }^{8}$ Ver: Natalia VELOSO GIRIBALDI - "Responsabilidad profesional médica: Aspectos jurídicos" en "Bioética en el Paciente Grave", Montevideo, 2015, Editorial Cuadrado, pág. 275. 
De la misma forma, también se plantea el tema del acceso a la historia clínica por parte del paciente con un trastorno mental, ya que si bien el médico tiene el deber de consignar su actuación en forma completa ${ }^{9}$, el acceso a todo lo que el psiquiatra consigna sobre la situación de salud del enfermo, puede tener connotaciones negativas para su tratamiento ${ }^{10}$.

En estos casos, resultaría aplicable la misma excepción que en el caso pasado, en tanto si de dicha historia surgieran afirmaciones que pudiesen ser contraproducentes para el tratamiento o para el vínculo médico-paciente, el acceso a la historia clínica podría ser restringido o postergado para una etapa posterior ${ }^{11}$

En cuarto lugar, se establecen derechos relativos a las condiciones de su internación estableciéndose que en todo momento sean supervisadas por la Comisión Nacional de Contralor de la Atención en Salud Mental (lit. m).

En quinto lugar, se les reconocen derechos relativos a su actividad tales como el de no ser sometidos a trabajos forzosos y a recibir una remuneración justa en caso de que realice objetos, obras o servicios que luego sean comercializados (lit. s); a acceder a actividades culturales y recreativas (lit. o) y a contar con asistencia letrada cuando se compruebe que la misma es necesaria para la protección de su persona o de sus bienes (lit. t).

En definitiva, puede concluirse que el paciente con un trastorno en su salud mental cuenta con todos los derechos reconocidos por nuestro ordenamiento para los pacientes y usuarios de la salud en general, con las particularidades y derechos específicos que para este tipo de casos reconoce la Ley de Salud Mental.

\section{PROBLEMAS QUE GENERA LA DISPOSICIÓN SOBRE DERECHOS PERSONALÍSIMOS EN EL PACIENTE INCAPAZ NATURAL E INTERDICTO}

\subsection{Enfoque general}

La posibilidad de emitir válidamente una voluntad se vincula con los conceptos jurídicos de capacidad de goce y de capacidad de obrar. Todas las personas son sujetos de derecho y como tales, tienen capacidad de goce dado que son susceptibles de ser titulares de derechos y obligaciones.

\footnotetext{
${ }^{9}$ La historia clínica, es definida como "un documento médico - legal complejo, que refleja los cambios acaecidos en las formas de la prestación asistencial y en la relación médico - paciente y, a través de su rol de medio de comunicación, constituye una condición sine quanon para la asistencia médica, un criterio de la lex artis y un aspecto crítico de la responsabilidad médica" (Hugo RODRÍGUEZ ALMADA y Mario DE PENA - "Historia Clínica: enfoque médico - legal desde la normativa vigente en Uruguay", en "Derecho Médico", Editorial B de F, Buenos Aires, 2001, pág. 511.) .

${ }^{10}$ En este sentido, no puede perderse de vista que, conforme al art. 16 de la Ley $\mathrm{N}^{\circ} 19.286$, se establece que: "La historia clínica es un documento fundamental en el acto médico, de ahí que: l. El paciente tiene derecho a obtener del médico un informe completo y veraz sobre la enfermedad que ha padecido y la asistencia que se le ha brindado. 2. El médico tiene el deber y el derecho de registrar el acto médico en una historia clínica, que pertenece al paciente pero que quedará bajo su custodia o bajo la de la institución a la que el médico pertenece. 3. Sólo en las circunstancias establecidas por la Ley tendrán acceso terceras personas a la información registrada en la historia clínica sin la autorización del médico y el paciente".

${ }^{11}$ Jorge GAMARRA - "Responsabilidad Civil Médica”, F.C.U., 1999, Tomo 1, pág. 178 a 183.
} 
No obstante, no todos los sujetos de derecho tienen capacidad de obrar porque, en determinadas circunstancias, el ordenamientojurídico les suprime la capacidad de ejercer por sí dichos derechos y de contraer obligaciones ${ }^{12}$

En cuanto a la diferencia entre la capacidad de goce y la de ejercicio se ha señalado que: "La primera es la aptitud para ser titular de derechos y obligaciones y como tal la ostentan todos los seres humanos; mientras que la segunda, carente de la generalidad de aquella, por no estar atribuida a todos los individuos, es la aptitud para ser destinatario de efectos jurídicos con el accionar del propio interesado. Consecuentemente, la posibilidad de intervenir por sí o personalmente en los negocios jurídicos lo distingue de la capacidad de la otra"13.

La capacidad de ejercicio o de obrar, se suprime por diversas razones. Una de ellas es la imposibilidad del sujeto de autogobernarse, lo que determina su incapacidad.

Nuestro Código Civil establece que serán considerados incapaces aquellos individuos $1^{\circ}$ ) que padezcan un trastorno mental permanente y $2^{\circ}$ ) que esa afección le impida al sujeto dirigirse a sí mismo o administrar sus negocios (art. art. 431 y 432 del Código Civil) ${ }^{14}$.

A su vez, corresponde distinguir a los incapaces naturales de los interdictos. Mientras que sobre los primeros no ha recaído una sentencia judicial que declare su incapacidad de obrar, en el caso de los interdictos sí existe dicho pronunciamiento.

Por su parte, si bien conforme al Código Civil en ambos casos la actuación de un incapaz (natural o interdicto) apareja nulidad absoluta, "en el caso de los primeros, la nulidad de su actuación va a depender de que se logre probar su inaptitud mental al otorgar el negocio cuya nulidad se impetra, mientras que, en el de los segundos, su interdicción les confiere una incapacidad abstracta, que no depende de su condición psicológica efectiva"15.

En efecto, la declaración de interdicción hace que ya no sea relevante si el sujeto estaba o no en sus facultades a la hora de celebrar un negocio. Por el contrario, una vez declarada la interdicción, se presume en forma absoluta que el interdicto era incapaz, aunque se demuestre que estaba plenamente lúcido al momento de brindar su consentimiento.

En estos casos, la ley dispone la necesidad de designar un representante legal que sea capaz de sustituir esa voluntad que, a la luz del ordenamiento jurídico, se reputa absolutamente nula.

Dicha solución jurídica de nuestro Código Civil, no presenta dudas cuando se trata de actos jurídicos de disposición de derechos patrimoniales de los incapaces, ya que a nadie le resulta extraño que los actos sobre los bienes de su patrimonio sean realizados mediante un representantelegal ${ }^{16}$.

\footnotetext{
${ }^{12}$ Jorge GAMARRA y Juan E. BLENGIO - "Tratado de Derecho Civil Uruguayo", cit., pág. 39 y ss.

${ }^{13}$ Walter HOWARD - "Derecho de la Persona”, Universidad de Montevideo, 2018, Volumen II, pág. 20 .

${ }^{14}$ En efecto, la permanencia del trastorno en el tiempo y la incapacidad para dirigirse a sí mismo también son elementos que el art. 2 de la Ley $\mathrm{N}^{\circ} 19.529$ tiene en cuenta para definir el concepto de trastorno mental.

${ }^{15}$ Walter HOWARD, Ob. cit. Pág. 39.

16 Ver: Geovana Andrea VALLEJO JIMÉNEZ, Mónica Isabel HERNÁNDEZ RÍOS y Adriana Elvira POSSO RAMÍREZ - "La capacidad jurídica de las personas con discapacidad en Colombia y los nuevos retos normativos" en Revista CES Derecho, Colombia, 2017, N 8, pág. 3 a 21.
} 
No obstante, la cuestión deviene más compleja cuando se trata de la disposición de derechos personalísimos del incapaz (como puede ser su derecho a la imagen, su derecho a interrumpir un embarazo, su derecho a desconocer la paternidad de un hijo, a donar un órgano para un familiar, etc.) ya que se trata de derechos que -como su nombre lo indicason inherentes a cada persona y su ejercicio por parte de los representantes legales, únicamente está previsto en determinados casos por la ley.

\subsection{Enfoque particular}

Los derechos personalísimos son aquellos que son inherentes a la personalidad humana y que se encuentran ligados a la propia dignidad y personalidad del ser humano.

Dadas sus características, se ha entendido tradicionalmente que el ejercicio de dichos derechos personalísimos únicamente puede ser realizado por sus titulares, con lo cual se plantea la dificultad de qué sucede con ellos cuando su titular adolece algún tipo de incapacidad o incluso, cuando se encuentra interdicto.

A modo de ejemplo, podría suceder que un incapaz quisiese donar órganos a un familiar, que quisiera abortar, realizarse un procedimiento de esterilización, desconocer la paternidad de un hijo, etc. En esos casos, si el titular de dichos derechos personalísimos no puede disponer de los mismos por estar incapacitado o interdicto, se plantea la cuestión de si su representante legal, podría disponer de ellos.

Si la respuesta es que ni el incapaz ni su representante, pueden disponer de esos derechos personalísimos, se produciría en los hechos una situación de verdadera incapacidad jurídica. Esto es, que ese sujeto de derecho no tendría -ya no capacidad de obrar respecto de estos derechos- sino que directamente, ya no podría ejercerlos de ninguna forma.

Si en cambio se entiende que para este tipo de derechos debe reconocerse cierta capacidad de obrar al incapaz, puede reconocérsele validez jurídica a las manifestaciones de voluntad que el incapaz realice si es que se demuestra que tiene conciencia y capacidad natural para comprender las consecuencias de los mismos.

Por otra parte, también cabría preguntarse qué sucedería si el incapaz no tuviese realmente capacidad natural para comprender el alcance de sus actos. En esos casos ¿el tutor podría disponer de los derechos personalísimos del incapaz?

Par dar respuesta a dichas interrogantes, es necesario distinguir entre dos hipótesis: a) que el incapaz natural o interdicto posea capacidad natural al momento de ejercer sus derechos personalísimos y b) que no la posea.

a) Caso del incapaz natural o interdicto que está en condiciones de tomar una decisión sobre sus derechos personalísimos.

En el estado actual del Derecho, se entiende que, si el incapaz natural o interdicto tiene capacidad para tomar una decisión sobre sus derechos personalísimos, debe recabarse su voluntad.

En este sentido, la doctrina española ha sostenido que: "no es obstáculo el estado de incapacitado para la realización de actos de ejercicio de los derechos personalísimos. La validez y eficacia del acto de ejercicio dependerá de que en ese momento posea condiciones 
intelectivas y volitivas que le permitan conocer y querer el alcance del acto y hacerse cargo de sus consecuencias. Y en este juicio acerca de la capacidad natural del sujeto, lejos de configurarse de forma abstracta, ha de proyectarse el acto concreto, considerado, asimismo, la complejidad y relevancia del mismo" ${ }^{17}$.

En la misma línea, nuestra doctrina ha señalado que: "por las características especiales de que están adornados estos derechos asume trascendencia la verdadera aptitud volitiva del discapacitado intelectual, con prescindencia de cuál sea su condición jurídica, esto es, si se halla o no declarado interdicto. De modo que, en tanto la persona respecto a cual se pretenda comprometer alguno de sus derechos personalísimos por parte de su representante legal, disfrute de una voluntad que sea juzgada idónea para comprender las repercusiones que va a sufrir con esa afectación, está facultada para intervenir con amplios poderes para la protección de los atributos que le son congénitos"18 .

Esta parece ser también la línea seguida por nuestro legislador en cuanto a la interrupción voluntaria del embarazo de una incapaz. En efecto, la Ley N 18.987 de 22 de octubre de 2012 dispone en su art. 8 que: "(Consentimiento de mujeres declaradas incapaces).- Si se tratara de una mujer declarada incapaz judicialmente, se requerirá el consentimiento informado de su curador y venia judicial del Juez competente del domicilio de la incapaz que -previa vista al Ministerio Público- evaluará la conveniencia del otorgamiento de la misma, respetando siempre el derecho de la mujer a procrear si el motivo de su incapacidad no le impidiere tener descendencia”.

Como puede apreciarse, a pesar de la interdicción y su consecuente presunción absoluta de nulidad establecida por el Código Civil, la ley dispone que en estos casos, será necesario respetar la voluntad de la mujer si su afección se lo permite.

En efecto, podría suceder que el curador solicitara la venia judicial y que, en el marco de dicho proceso, el Juez recabara la opinión de la incapaz y que ésta manifestara su intención de procrear. En ese caso, si la incapacidad no le impidiera tener descendencia, debería respetarse la voluntad de la incapaz denegándose la referida venia para proseguir con el proceso de interrupción voluntaria del embarazo.

Lo mismo vale decir para la obtención del consentimiento informado para el caso de niñas, niños y adolescentes con trastornos mentales, para los cuales el art. 23 de la Ley $\mathrm{N}^{\circ}$ 19. 529 establece que: "se requerirá el consentimiento informado del padre, madre o tutor y de acuerdo a la edad y condición mental del sujeto, se solicitará su consentimiento”.

En efecto, es evidente que el niño, niña o adolescente que padece un trastorno mental es un incapaz, no obstante, la ley igualmente prevé la necesidad de recabar su opinión ya que entiende que hay un derecho personalísimo involucrado.

En este sentido, si bien la ley no es clara en cuanto a si el consentimiento del representante es acumulativo con el del menor o si en caso de que el menor pueda brindarlo, es excluyente del mismo, lo importante es que si el menor está en condiciones de brindar dicho consentimiento, debe recabárselo y en caso de que no lo brinde, impedirá la prestación del tratamiento a brindarse.

\footnotetext{
17 Natalia ÁLVAREZ LATA - "El ejercicio de acciones y derechos personalísimos de la persona incapacitada" Revista de Derecho Privado y Constitución, No 15, Enero -Diciembre de 2005 , pág. 23.

${ }^{18}$ Walter HOWARD - "Derecho de la Persona”, cit., Volumen II, pág. 741.
} 
En cuanto a los procesos de esterilización de incapaces, evidentemente también estamos ante la disposición de una capacidad funcional del propio cuerpo, por lo que -si está en condiciones de otorgarla- sería necesario recabar la voluntad del paciente involucrado.

$\mathrm{Al}$ respecto, se ha sostenido que: "en caso de que se requiera la esterilización reproductiva de una persona con limitaciones de entidad en su psiquis, la autorización debe ser denegada, salvo el caso que ella se encuentre recomendada por razones terapéuticas, en las cuales entran en conflicto otros derechos inherentes a la persona incapaz, como el derecho a la vida o a la salud. Por fuera de ese caso, incumplen sus deberes de protección tanto los representantes legales que pretenden coartar la libertad reproductiva del sujeto, como aquel magistrado que, desconociendo preceptos constitucionales (art. 7 y 72 de la Carta), autorizara esa intervención. Se trata de derechos que, como se anotó, tienen el rasgo de indisponibilidad para quien no es titular y la voluntad del representante es ineficiente para alcanzar el resultado perseguido" 19 .

En consecuencia, la solución de nuestro ordenamiento parecería ser que para la disposición de los derechos personalísimos, deber recabarse la voluntad del incapaz independientemente de si el mismo ha sido declarado incapaz o simplemente es incapaz natural, siempre y cuando su incapacidad le permita conocer el alcance y consecuencias de sus actos, aspecto que deberá ser determinado por un profesional de la salud.

No obstante, dicha solución no da respuesta a qué es lo que sucede cuando un incapaz carece de discernimiento para comprender el alcance de dicha manifestación de voluntad respecto de un derecho personalísimo. En esos casos, corresponde analizar si el representante legal puede igualmente disponer de dichos derechos personalísimos o si a su respecto, se produce una verdadera incapacidad jurídica del sujeto.

b) Caso del incapaz natural o interdicto que no está en condiciones de tomar una decisión sobre sus derechos personalísimos.

En estos casos, la doctrina tradicional ha entendido que, dado que se trata de derechos personalísimos, no es posible que el representante legal ejerza su representación, no alcanzando su designación como representante para sustituir la voluntad del incapaz en estos aspectos.

En esta línea, se ha sostenido que: "salvo en los casos en que haya norma y régimen jurídico concreto para el ejercicio de ciertos derechos fundamentales, en los demás será el juez quien tenga la última palabra y decisión al respecto: bien con su necesaria aprobación de la del representante legal o adoptando él una decisión autónoma y única a petición del representantelegal ${ }^{20}$ ".

En definitiva, debe concluirse que el principio general es que para la disposición de derechos personalísimos, la voluntad del incapaz debe ser recabada y considerada con independencia de su estatus legal, siempre y cuando en ese momento tenga la capacidad natural para tener conciencia de sus actos y de sus consecuencias. Asimismo, en caso de que a juicio del profesional de la salud, el incapaz no esté en condiciones de emitir una voluntad libre y consiente, el representante no podrá por sí solo representar al incapaz sin

${ }^{19}$ Walter HOWARD - "Derecho de la Persona", cit., Volumen II, pág. 745.

${ }^{20}$ José GIL RODRÍGUEZ - "Comentario al art. 267” en "Comentario del Código Civil”, Madrid, Ministerio de Justicia, 1991, Tomo I, pág. 786. 
una autorización judicial, salvo que la ley expresamente le otorgue dicha facultad para ese caso concreto.

\section{CONSENTIMIENTO INFORMADO EN SALUD MENTAL}

\subsection{El consentimiento informado}

El consentimiento informado en salud mental presenta ciertas particularidades propias de la afectación de la capacidad de discernir del paciente, generada por la propia patología de base que le afecta.

A primera vista, la existencia de un trastorno mental y la posibilidad de brindar un consentimiento válido pueden parecer contradictorios, no obstante, tal como se vio, en algunos casos dicha contraposición puede ser únicamente aparente siendo posible recabar el consentimiento informado del paciente.

En efecto, el consentimiento informado "significa que cierta información acerca del procedimiento médico, sus riesgos, beneficios y efectos secundarios, debe comunicarse al paciente para permitirle tomar una decisión que refleje su voluntad”21.

A su vez, dicho consentimiento informado, se encuentra consagrado en el art. $37^{\circ}$ del Decreto $\mathrm{N}^{\circ} 258 / 992$, al disponer que "El paciente tiene derecho a recibir toda la información necesaria para autorizar con conocimiento de causa cualquier tratamiento o procedimiento que le practiquen".

En cuanto al contenido de dicho consentimiento, se ha entendido que el mismo debe brindar información concreta y específica del procedimiento al que se somete y no estar redactado en forma genérica, sino en referencia concreta al procedimiento que se va a realizar. Asimismo, se ha señalado que el mismo tiene que brindar una idea razonable de los riesgos a los que se somete el paciente. No de todos los riesgos, sino a de aquellos normales o razonables derivados del procedimiento que se va a realizar ${ }^{22}$

Pues bien, en el caso del paciente que padece una enfermedad mental, el legislador ha considerado que también resulta necesario recabar su consentimiento a pesar de su enfermedad, estableciendo expresamente en el art. 23 de la Ley $N^{\circ} 19.529$ que: "Se requerirá el consentimiento informado de la persona para la realización de las intervenciones biológicas y psicosociales, propuestas en la estrategia terapéutica, el que deberá ser obtenido de conformidad y con las garantías y excepciones dispuestas por el artículo 11 de la Ley $\mathrm{N}^{\circ} 18.335$, de 15 de agosto de 2008 , la presente ley y demás normativa aplicable. En el caso de niñas, niños y adolescentes con trastornos mentales se requerirá el consentimiento informado del padre, madre o tutor y de acuerdo a la edad y condición mental del sujeto, se solicitará su consentimiento. Es obligación de los profesionales intervinientes brindar información sobre la naturaleza del trastorno mental, diagnóstico y tratamiento propuesto, beneficios esperados y posibles riesgos de éste, eventualidad de hospitalización, condiciones y finalidad de la misma. La información deberá ser suficiente, continua y en lenguaje comprensible para la persona, teniendo en cuenta su singularidad biopsicosocial y cultural.

\footnotetext{
${ }^{21}$ Jorge GAMARRA - "Responsabilidad Civil Médica", cit., Tomo I, pág. 154.

${ }^{22}$ Ver: Sentencia N 158/2014 de 29 de septiembre de 2014 del TAC 1, Caso 995, publicado en la Revista de Doctrina y Jurisprudencia de Derecho Civil, pág. 838.
} 
Las personas con discapacidad tienen derecho a recibir la información a través de los medios y tecnologías adecuadas para su comprensión. El consentimiento informado se hará constar en la historia clínica, al igual que la ausencia de él en los casos en que lo autorice la normativa aplicable".

En definitiva, conforme a la Ley de Salud Mental, el paciente con un trastorno mental tiene el derecho a que se recabe su consentimiento informado antes de realizársele las intervenciones biológicas y psicosociales, propuestas en la estrategia terapéutica. Dicho derecho a consentir un tratamiento sobre su sique, es sin dudas un derecho personalísimo al que resultan plenamente aplicables las consideraciones realizadas en el apartado anterior.

\section{2. ¿Cuándo es válido el consentimiento del incapaz en salud mental?}

En tanto el derecho a que se recabe el consentimiento informado es un derecho personalísimo del incapaz, le resultan plenamente aplicables las consideraciones vertidas anteriormente sobre la necesidad de recabar la voluntad del paciente si el profesional tratante entiende que está en condiciones de manifestarla.

Sin perjuicio de ello, no debe olvidarse que el consentimiento informado es un elemento esencial de la actuación médica y que, conforme a cierta parte de la doctrina y jurisprudencia, la no obtención del mismo es causa autónoma de responsabilidad civil ${ }^{23}$.

Teniendo en cuenta dicho extremo y las dificultades probatorias que pueden surgir a la hora de demostrar la validez de un consentimiento, resulta de fundamental importancia distinguir las hipótesis en las cuales el paciente es un incapaz natural y en las cuales es un incapaz interdicto.

En el caso del paciente que no está interdicto (incapaz natural) no existen mayores problemas ya que en estos casos, quien estará en condiciones de determinar si ese paciente está no en condiciones de comprender y consentir un tratamiento, técnica o estudios a realizarse, será el psiquiatra. En efecto, será el profesional quien deberá analizar en cada caso si el paciente bajo análisis está o no en condiciones de brindar su consentimiento válido y libre y comprender el alcance y la finalidad del procedimiento y así consignarlo en su historia clínica ${ }^{24}$

Al respecto, se ha señalado que: "Actualmente, a los pacientes seles reconoce autonomía para tomar decisiones si manifiestan capacidad para ello, actúan intencionalmente, en ausencia de influencias externas, y expresan su voluntad tomando en cuenta las consecuencias que dichas decisiones tienen para su salud y para su vida futura. Cumplidas las condiciones anteriores, el acto del médico será beneficente si respeta la autonomía del paciente. En cambio, el acto médico resultará maleficente cuando, sin una correcta evaluación de la capacidad, se permite a un paciente incapaz desde un punto de vista

${ }^{23}$ Jorge GAMARRA - "Responsabilidad Civil Médica", cit., Tomo I, pág. 163 y Sentencia de la SCJ N 188/2013 de 13 de marzo de 2013 en Revista de Doctrina y Jurisprudencia de Derecho Civil, FCU, Año II, 2014, Tomo II, pág. 748 Caso N 941.

${ }^{24}$ Margarita ISLAS-SAUCILLO y Heberto MUÑOZ CUEVAS - "El consentimiento informado. Aspectos bioéticos” en Revista Médica del Hospital General de México, Vol. 63, Núm. 4, Oct.-Dic. 2000, pág. $267-273$. 
sanitario, que tome decisiones que pueden producirle daño. Frente a un paciente catalogado como incapaz para tomar decisiones es necesario entregar el poder de tomarla a un tercero (generalmente un familiar), ya sea en forma transitoria o definitiva, conforme lo señala la ley"25.

En el caso del paciente que está interdicto la cuestión es más complicada ya que si bien existen desarrollos doctrinarios y disposiciones legislativas que reconocen capacidad de obrar al interdicto para disponer de sus derechos personalísimos, la realidad es que las disposiciones del Código Civil que establecen la presunción absoluta de nulidad de la actuación del paciente interdicto, siguen vigentes y pueden ser tomadas en cuenta para desconocer el consentimiento (aunque el paciente lo haya otorgado en forma absolutamente lúcida).

En estos casos, dada la gravedad de las consecuencias que pueden derivar de no poseer un consentimiento informado válido y estando aún vigentes las referidas disposiciones del Código Civil, entendemos que resultaría conveniente igualmente recabar el consentimiento firmado de los representantes legales.

En este sentido, no cabe duda de que, si está en condiciones de brindarlo, el consentimiento del paciente interdicto también debe ser recabado (ya que así lo indica el art. 23 de la Ley de Salud Mental para todos los pacientes). No obstante, a los efectos de evitarse problemas probatorios o de interpretación normativa, entendemos que adicionalmente no debería prescindirse del consentimiento del representante legal del interdicto.

En este caso, podría suceder que exista una divergencia de criterios entre el representante legal y el paciente interdicto que se encuentra en condiciones de emitir el consentimiento. A modo de ejemplo, podría suceder que el representante legal consienta un procedimiento y el interdicto, consciente de ello, no lo haga. $\mathrm{O}$ viceversa.

En estos casos, entendemos que una lectura armónica de las disposiciones sobre derechos personalísimos, de la normativa del Código Civil, de la Ley de Salud Mental, Ley de Protección Integral de Personas con Discapacidad N 18.651 y de la Convención sobre los Derechos de las Personas con Discapacidad ratificada por Uruguay, debería interpretarse que debe primar la voluntad del incapaz, aun cuando esté interdictado.

Dicha solución se impone en tanto una declaración abstracta de interdicción no puede anteponerse a una decisión conscientemente emitida a criterio de un profesional, que dispone que no se consiente o que sí se consiente un determinado tratamiento que se realizará sobre su persona.

En definitiva, entendemos que es válido el consentimiento informado obtenido por una persona que no está declarada interdicta siempre y cuando el profesional de la salud certifique que efectivamente estaba en condiciones de otorgarlo. Asimismo, en caso de un paciente interdicto que está en condiciones de brindar su consentimiento, debe recabárselo sin perjuicio asimismo, de recabar el consentimiento de sus representantes legales, debiendo primar el primero de ellos en caso de contradicción.

${ }^{25}$ Gladys BÓRQUEZ, Gina RAINERI, Mireya BRAVO - "La evaluación de la «capacidad de la persona»: en la práctica actual y en el contexto del consentimiento informado" en Revista Médica de Chile, Santiago de Chile, Octubre de 2004, Volumen 132, N.10, versión digital: http://dx.doi.org/10.4067/S003498872004001000013 . 


\section{HOSPITALIZACIÓN VOLUNTARIA, INVOLUNTARIA Y JUDICIAL}

\subsection{Caracteres generales de la hospitalización}

El art. 24 de la Ley de Salud Mental $N^{\circ} 19.529$ regula la hospitalización como un recurso terapéutico de carácter restringido que deberá llevarse a cabo solo cuando aporte mayores beneficios que el resto de las opciones terapéuticas ${ }^{26}$.

En efecto, se procurará que sea lo más breve posible y que en ningún caso tenga como fin resolver problemas sociales o de vivienda. En este caso, la prohibición de la norma es clara. Lo que busca es que la internación no se indique como un mecanismo para solucionar los problemas de vivienda o familiares de un paciente que puede vivir solo y autogobernarse, pero por ejemplo, no tiene donde vivir. En estos casos, son otros mecanismos de contención social los que deben activarse y no la internación en un centro asistencial.

Distinto es el caso del enfermo mental que no puede autogobernarse y no tiene donde vivir o no tiene una red de contención familiar que lo sostenga. Estos casos no quedan alcanzados por la prohibición porque no es internado porque no tiene donde vivir o porque no tiene quien lo cuide, sino para proteger al paciente que no puede valerse por sí solo.

Asimismo, para estos casos el art. 26 de la Ley prevé diferentes modalidades de hospitalización que pueden contemplar diferentes realidades de los pacientes tales como las de la internación a tiempo completo o parcial diurna y nocturna o inclusive, domiciliaria.

Por su parte, la extensión de la cobertura en ningún caso podrá estar sujeta a límites temporales de cobertura, sea cual sea la edad de la persona usuaria (art. 25). Dicha disposición, ha generado problemas en su aplicación ya que la ley es de orden público y aplica a todos los prestadores de salud que brinden servicios de salud mental.

En consecuencia, tratándose de una norma de orden público, los prestadores (sean públicos o privados) no podrán pactar con los usuarios limitaciones contrarias al art. 25 que restringieran los límites temporales de la internación.

En cuanto a los requisitos para la hospitalización, debe señalarse que los mismos varían según el tipo de internación que se trate. No obstante, existen requisitos generales que deben cumplirse en caso de que un paciente sea hospitalizado. Dichos requisitos generales, conforme al art. 27 de la Ley son:

a) evaluación, diagnóstico y motivos que la justifican, con la firma de un profesional médico;

b) obtención del consentimiento informado de la persona o del representante legal cuando corresponda, tramitado según lo dispuesto en el artículo 23 de la presente ley.

Por su parte, el art. 38 de la Ley dispone que: “(Establecimientos asilares y monovalentes).- Queda prohibida la creación de nuevos establecimientos asilares y monovalentes, públicos y privados desde la entrada en vigencia de la presenteley. Los ya existentes deberán adaptar su funcionamiento a las prescripciones de esta ley, hasta su sustitución definitiva

${ }^{26}$ Magda DIMENSTEIN - "La reforma psiquiátrica y el modelo de atención psicosocial en Brasil: en busca de cuidados continuados e integrados en salud mental” en Revista CS, Intervención Psicosocial, Brasil, Río Grande do Norte, N 11, Edición Enero-Junio 2013, pag. 43-72. 
por dispositivos alternativos, de acuerdo a los que establezca la reglamentación. Queda igualmente prohibida, a partir de la vigencia de la presente ley, la internación de personas en los establecimientos asilares existentes. Se establecerán acciones para el cierre definitivo de los mismos y la transformación de las estructuras monovalentes. El desarrollo de la red de estructuras alternativas se debe iniciar desde la entrada en vigencia de esta ley. El Poder Ejecutivo establecerá en la reglamentación de la presente ley el cronograma de cierre de los establecimientos asilares y estructuras monovalentes. El cumplimiento definitivo del cronograma no podrá exceder temporalmente el año 2025 ”.

En este caso, cuando la ley se refiere a "estructuras monovalentes" está haciendo referencia a establecimientos exclusivamente psiquiátricos por contraposición a los Hospitales Generales donde se tratan todo tipo de patologías, no únicamente mentales.

Lo que se busca es el cambio del paradigma en la estructura asistencial pasando de estructuras asistenciales estrictamente destinadas a pacientes con enfermedades mentales a salas especializadas en Hospitales Generales.

La ley asimismo encomienda a la reglamentación el proceso progresivo de reconversión del sistema desde el modelo monovalente al modelo inclusivo, en el cual las salas de pacientes con enfermedades mentales estarían integradas en hospitales generales. Sin embargo, a pesar de que el Decreto del Poder Ejecutivo No $^{\circ} 226 / 018$ de 16 de julio de 2018 reglamentó la Ley de Salud Mental, nada dijo sobre cómo se instrumentará dicho proceso.

No obstante, con independencia de lo que diga la reglamentación, conforme al texto legal vigente, el Estado tiene la obligación de brindar asistencia a la salud para aquellos carentes de recursos (art. 44 de la Constitución) por lo que, si al 2025 se encuentran cerrados los centros monovalentes, deberá garantizarse la asistencia a la salud mental en otros centros, so pena de incurrir en responsabilidad.

\subsection{Hospitalización voluntaria}

La hospitalización voluntaria corresponde cuando "profesionalmente se determine la conveniencia de tratar a la persona con trastorno mental a través de hospitalización" (art. 28).

En estos casos, la hospitalización es consentida por el paciente y en cualquier momento, puede decidir por sí mismo el abandono de la hospitalización.

Sin perjuicio de ello, al momento de gestionar el consentimiento informado para la hospitalización, se le debe hacer saber a la persona que los profesionales intervinientes podrán impedir su externación si se dieran las condiciones para una hospitalización involuntaria (esto es: que exista riesgo inminente de vida para la persona o para terceros o que esté afectada su capacidad de juicio, y el hecho de no hospitalizarla pueda llevar a un deterioro considerable de su condición o impedir que se le proporcione un tratamiento adecuado que sólo pueda aplicarse mediante la hospitalización).

En estos casos, si no se verifica alguna de las causales habilitantes de la internación involuntaria, el profesional actuante no podrá retener al paciente contra su voluntad so pena de incurrir en responsabilidad. Sin perjuicio de ello, podría ocurrir que sin verificarse alguna de las causales establecidas en el art. 30 de Ley para la internación involuntaria, igualmente no sea recomendable otorgarle el alta la paciente. 
En esos casos, se deberá dejar ir al paciente sin perjuicio de hacerle saber y de informarle que se abandona la internación contra la prescripción médica. Esto es, que a criterio del médico el paciente debería permanecer internado pero que no estando dadas en ese momento las circunstancias previstas por la ley para la internación involuntaria, el paciente abandona por su decisión la internación.

En cuanto a las formalidades de la internación voluntaria, el art. 29 establece que el Director Técnico del prestador de salud a cargo deberá comunicar a la Comisión Nacional de Contralor de la Atención en Salud Mental y a la Institución Nacional de Derechos Humanos, las hospitalizaciones voluntarias e involuntarias que se prolonguen por más de cuarenta y cinco días corridos, dentro de las setenta y dos horas de vencido dicho plazo. Asimismo, el art. $1^{\circ}$ del Decreto $N^{\circ} 226 / 18$ reglamenta la forma en que deberá realizarse dicha notificación.

\subsection{Hospitalización involuntaria}

La libertad es un derecho fundamental de todo ser humano establecido en la Constitución y para cuya limitación, se requiere una ley formal dictada por razones de interés general (art. 7 y 10 de la Constitución) ${ }^{27}$.

Por esta razón, la posibilidad de que exista una internación contra la voluntad de un individuo debe estar prevista y regulada por una ley y tiene que tener como justificación el interés general.

En este caso, primero la Ley $\mathrm{N}^{\circ} 9.581$ y actualmente la Ley $\mathrm{N}^{\circ} 19.529$, prevén la posibilidad de internar contra su voluntad a una persona cuando exista riesgo inminente de vida para él o para terceros o cuando esté afectada su capacidad de juicio, y el hecho de no hospitalizarla pueda llevar a un deterioro considerable de su condición o impedir que se le proporcione un tratamiento adecuado que sólo pueda aplicarse mediante la hospitalización.

En este sentido, se entiende que existe riesgo inminente de vida para la persona o terceros "cuando se presente una situación que, debido a consideraciones clínicas adecuadamente fundadas en forma clara y precisa, determine una posibilidad cierta de muerte de próxima ocurrencia" (art. 2 del Decreto $N^{\circ}$ 226/18). Establece asimismo que dichas condiciones deberán ser recabadas en la Historia Clínica.

En cuanto a las formalidades para la internación involuntaria, el art. 31 prevé que se recabe:

a) declaración firmada por el familiar más cercano, allegado o representante legal si lo hubiera, solicitando su hospitalización y expresando su conformidad con la misma. Si no hubiera familiar, allegado ni representante legal, o habiéndolos se negarán a consentir la hospitalización y se dieran los supuestos del artículo 30 de la presente ley, se podrá realizar cumpliendo únicamente con el dictamen profesional a que refiere el literal siguiente del presente artículo;

${ }^{27}$ Martín RISSO FERRAND - "Algunas garantías básicas de los derechos humanos", F.C.U, Montevideo, 2008, pág. 61 y sigtes. 
b) dictamen profesional del servicio de salud que realice la hospitalización, determinando la existencia de los supuestos establecidos en el artículo 30 de la presente ley, firmado por dos profesionales médicos que no tengan relación de parentesco, amistad o vínculos económicos con la persona, uno de los cuales deberá ser especialista en psiquiatría. En el abordaje terapéutico posterior deberá intervenir un equipo interdisciplinario; $y$

c) informe sobre las instancias previas implementadas, si las hubiere.

En cuanto a la forma de notificación, el art. 32 de la Ley establece que: "Toda hospitalización involuntaria deberá ser notificada por el Director Técnico del prestador a cargo, a la Comisión Nacional de Contralor de la Atención en Salud Mental, la institución Nacional de Derechos Humanos y al Juez competente dentro de las veinticuatro horas siguientes, con los fundamentos que sustenten la misma y las constancias a que refiere el artículo 31 de la presente ley. El Juez podrá requerir, en caso de considerarlo necesario, información ampliatoria a los profesionales tratantes o indicar peritajes externos que no perjudiquen la evolución del tratamiento, tendientes a confirmar los supuestos que justifiquen la medida”.

\subsection{Hospitalización judicial}

El art. 33 de la Ley prevé la posibilidad de que un $\mathrm{Juez}^{28}$ disponga una hospitalización involuntaria cuando cuente con informe médico que la justifique, pudiendo en cualquier momento, pedir al prestador a cargo de la hospitalización, información sobre el curso del proceso asistencial, a fin de reevaluar si persisten las razones para la continuidad de la medida. Asimismo, el Director Técnico del centro asistencial donde se realizóla internación, tendrá veinticuatro horas para notificar de dicha internación a la Comisión Nacional de Contralor de la Atención en Salud Mental, la institución Nacional de Derechos Humanos.

Por su parte, cuando estén dadas las condiciones para el alta de la persona, el Director Técnico del prestador deberá notificarlo a la Comisión Nacional de Contralor de la Atención en Salud Mental y al Juez y éste último, deberá expedirse al respecto en un plazo no mayor a tres días hábiles a contar desde el día siguiente al de la notificación.

En la práctica, dicha disposición ha generado importantes problemas en tanto existe una sustancial cantidad de pacientes internados por orden judicial, cuya alta ha sido solicitada por los Directores Técnicos de los Prestadores de Salud, que habiendo transcurrido el plazo legal de 3 días, no han obtenido aún un pronunciamiento judicial que autorice su salida.

En efecto, más allá del criterio del médico actuante que entiende que el paciente hospitalizado está en condiciones de irse de alta, la legislación determina que hasta que el Juez no se pronuncia, el paciente no puede abandonar la institución.

Dicho problema de antiquísima data, también se planteaba en la anterior ley y se mantiene en la presente, siendo uno de los principales temas a solucionar para la mejora de todo el Sistema de Salud Mental y sobre todo, de las condiciones de hospitalización.

${ }^{28} \mathrm{El}$ juez competente en cada caso para disponer de la internación judicial dependerá de la naturaleza del asunto que se esté tramitando, pudiendo ser dispuesta por el Juez Penal o por el Juez de Familia en su caso. 


\section{ASPECTOS DE ORGANIZACIÓN}

En cuanto a los aspectos orgánicos, la Ley de Salud Mental señala que el Ministerio de Salud Pública será el encargado de aplicarla a los prestadores públicos y privados ${ }^{29}$ y que deberá asimismo, elaborar y aprobar un Programa Nacional de Salud Mental (art. 7 y 8).

Asimismo, en su art. 39 crea la Comisión Nacional de Contralor de la Atención en Salud Mental como "organismo" dependiente del Ministerio de Salud Pública ${ }^{30}$.

Por su parte, el art. 5 del Decreto $\mathrm{N}^{\circ}$ 226/18 sustituye correctamente la palabra "organismo" por "órgano" y agrega además que se trata de un órgano desconcentrado del Ministerio de Salud Pública con los cometidos que le otorga la ley.

En cuanto a su conformación, el art. 41 de la Ley establece que sus miembros serán designados por el Poder Ejecutivo, que serán de carácter honorario y que estará integrada por:

a) dos miembros representantes del Ministerio de Salud Pública, uno de los cuales deberá acreditar conocimientos, formación y experiencia en el tema de la salud mental. Uno de ellos la presidirá;

b) tres miembros representantes de la Universidad de la República designados uno a propuesta de la Facultad de Medicina, otro a propuesta de la Facultad de Psicología y otro a propuesta de la Facultad de Derecho. Se observará que todos estén vinculados a la temática de la presente ley;

c) un miembro representante de las organizaciones más representativas de los trabajadores de la salud mental;

d) un miembro representante de las sociedades científicas vinculadas a la salud mental;

e) un miembro representante de las organizaciones más representativas de las personas con trastorno mental;

f) un miembro representante de las organizaciones más representativas de los familiares de las personas con trastorno mental; y

g) un representante de las organizaciones de la sociedad civil en salud mental y derechos humanos.

Por su parte, el art. 40 establece los cometidos de dicho órgano, otorgándole competencia en todo el territorio nacional y poderes jurídicos de inspección muy amplios para su cumplimiento. Asimismo, se prevéla posibilidad de elevar sus actuaciones al Ministerio de Salud Pública a los efecto de solicitar se impongan sanciones en caso de detectar violaciones de la normativa sanitaria.

${ }^{29}$ Natalia VELOSO GIRIBALDI - "Régimen de prestación pública" en Carlos E. DELPIAZZO (Coordinador) - "Régimen de Asistencia a la Salud", cit. pág. 101 y sigtes; y "Régimen de prestación privada" en Carlos E. DELPIAZZO (Coordinador) - "Régimen de Asistencia a la Salud", cit. pág. 117 y y sigtes.

${ }^{30}$ Posteriormente en el art. 5 del Decreto $N^{\circ}$ 226/18 sustituye correctamente la palabra "organismo" por "órgano". 


\section{CONCLUSIÓN}

A partir del dictado de la Ley $N^{\circ} 19.529$ de Salud Mental, el Uruguay deja atrás una normativa que llevaba más de 80 años de vigencia y se pone a tono con las Convenciones ratificadas por el país, dándole un rol central al paciente con un trastorno mental y erigiéndolo en el centro de atención de la normativa, como sujeto de Derecho susceptible de ejercer sus derechos y obligaciones conformes a sus capacidades reales.

\section{BIBLIOGRAFÍA CONSULTADA}

ÁLVAREZ LATA, Natalia - "El ejercicio de acciones y derechos personalísimos de la persona incapacitada" Revista de Derecho Privado y Constitución, N 15, Enero -Diciembre de 2005, pág. 23.

BÓRQUEZ, Gladys RAINERI, Gina y BRAVO, Mireya - "La evaluación de la "capacidad de la persona»: en la práctica actual y en el contexto del consentimiento informado" en Revista Médica de Chile, Santiago de Chile, Octubre de 2004, Volumen 132, N.10, versión digital: http://dx.doi.org/10.4067/ S0034-98872004001000013.

CESTAU, Saúl D - "Personas", F.C.U., Montevideo, 1997, Volumen II, pág. 123 y sgtes.

DEI-CAS, Bárbara - "Derechos y Deberes de los Pacientes y Usuarios" en Carlos E. DELPIAZZO (Coordinador) - "Régimen de Asistencia a la Salud", F.C.U., Montevideo, 2018, Segunda Edición Ampliada y Actualizada, pág. 175 y ss.).

DELPIAZZO, Carlos E - "Alcance del rol tutelar del Estado a menores, discapacitados y adultos mayores" en Anuario Uruguayo Crítico de Familia y Sucesiones (Montevideo, 2016), N 4, pág. 135 y sgtes.; y "Derecho Administrativo Especial", A.M.F., Montevideo, 2017, volumen 2, tercera edición actualizada y ampliada, pág. 173 y sgtes.

DHANDA, Amita- "Construyendo un nuevo léxico de derechos humanos: La Convención sobre los Derechos de las personas con discapacidad" en SUR, Revista internacional de Derechos Humanos, Año 5, Número 8, Junio de 2008, Edición en español, pág. 48.

DIMENSTEIN, Magda - "La reforma psiquiátrica y el modelo de atención psicosocial en Brasil: en busca de cuidados continuados e integrados en salud mental" en Revista CS, Intervención Psicosocial, Brasil, Río Grande do Norte, No 11, Edición Enero-Junio 2013, pag. 43-72.

GAMARRA, Jorge - "Responsabilidad Civil Médica", F.C.U., 1999, Tomo 1, pág. 178 a 183.

GAMARRA, Jorge y BLENGIO, Juan - "Tratado de Derecho Civil Uruguayo", F.C.U., 2001, Tomo X, $5^{\circ}$ Edición, pág. 168 y ss.).

GIL RODRÍGUEZ, José - "Comentario al art. 267" en "Comentario del Código Civil", Madrid, Ministerio de Justicia, 1991, Tomo I, pág. 786.

HOWARD, Walter - "Derecho de la Persona", Universidad de Montevideo, 2018, Volumen II, pág. 553.

ISLAS-SAUCILLO, MARGARITA y MUÑOZ CUEVAS, Heberto - "El consentimiento informado. Aspectos bioéticos" en Revista Médica del Hospital General de México, Vol. 63, Núm. 4, Oct.-Dic. 2000, pág. $267-273$.

RISSO FERRAND, Martín - "Algunas garantías básicas de los derechos humanos", F.C.U, Montevideo, 2008, pág. 61 y sigtes.

RODRÍGUEZ ALMADA, Hugo y DE PENA, Mario - "Historia Clínica: enfoque médico - legal desde la normativa vigente en Uruguay", en "Derecho Médico", Editorial B de F, Buenos Aires, 2001, pág. 511.).

VALLEJO JIMÉNEZ Geovana Andrea, HERNÁNDEZ RÍOS, Mónica Isabel y POSSO RAMÍREZ, Adriana Elvira - "La capacidad jurídica de las personas con discapacidad en Colombia y los nuevos retos normativos" en Revista CES Derecho, Colombia, 2017, № 8, pág. 3 a 21.

VELOSO GIRIBALDI, Natalia - "Régimen de prestación pública" en Carlos E. DELPIAZZO (Coordinador) - "Régimen de Asistencia a la Salud", cit. pág. 101 y sigtes; y "Régimen de prestación privada" en Carlos E. DELPIAZZO (Coordinador) - "Régimen de Asistencia a la Salud", cit. pág. 117 y y sigtes.

VELOSO GIRIBALDI, Natalia - "Responsabilidad profesional médica: Aspectos jurídicos" en "Bioética en el Paciente Grave”, Montevideo, 2015, Editorial Cuadrado, pág. 275.

Fecha de recepción: 14 agosto 2018.

Fecha de aceptación: 29 setiembre 2018. 